\title{
ANGUSTIA Y REAL: LA DIALÉCTICA DEL VELO
}

\author{
ANXIETY AND THE REAL: THE DIALECTIC OF VEIL
}

\author{
Oriol Alonso Cano* \\ Héctor García de Frutos** \\ Universidad de Barcelona \\ Barcelona-España \\ Recibido 13 de noviembre 2012/Received November 13, 2012 \\ Aceptado 7 de febrero 2013/Accepted February 7, 2013
}

\begin{abstract}
RESUMEN
El fenómeno de la angustia se erige en una de las problemáticas fundamentales en el discurso contemporáneo. En especial, el paradigma de Heidegger, retomando las problemáticas suscitadas por el planteamiento de Kierkegaard, aborda este tema, concluyendo que la angustia es la vía de acceso a la propiedad (Eigentlichkeit) del Dasein. Expresado en otros términos, la angustia desoculta al sujeto su radical finitud, arrancándolo de la impropiedad del discurso social imperante.

La angustia en psicoanálisis es el reverso del deseo. El objeto que revela es propiamente el objeto inmundo que se arranca del cuerpo del Otro, moviliza el deseo, y posibilita la escena de goce que es el fantasma. La operación analítica desvela esta verdad, y permite al sujeto contemporáneo escapar del estancamiento en su narcisismo. El psicoanalista Jacques Lacan y Heidegger coinciden en la dialéctica del velo, pero sus aproximaciones a la verdad difieren.
\end{abstract}

Palabras Clave: Angustia, Dasein, Existencia, Psicoanálisis.

\begin{abstract}
The phenomenon of anguish rises as one of the capital problems in contemporary discourse. Especially Heidegger's paradigm, reintroducing the problematic in Kierkegaard's thinking, tackles this issue, concluding that anxiety is the way of access to the property (Eigentlichkeit) of Dasein. In other terms, anguish reveals the subject in its radical finitude, pulling him out from the impropriety of the prevailing social discourse.

Anxiety in psychoanalysis is the reverse of desire. It reveals an object, which is properly the filthy object we extirpate from the Other's body, the one that animates desire and
\end{abstract}

* Departamento de Historia de la Filosofía, Estética y Filosofía de la Cultura. Facultad de Filosofía. Universidad de Barcelona y Universidad Oberta de Catalunya. España.

** C/ Sardenya, 153, Escalera Derecha, 5 $1^{\text {a }}$. C.P. 08013. Barcelona. España. E-mail: hector.garciadefrutos@gmail.com 
makes possible the 'jouissance' scene called phantasm. The analytical operation uncovers this truth, and allows the contemporary subject to escape from the stagnation in narcissism. The psychoanalyst Jacques Lacan and Heidegger coincide in the dialectic of the veil, but their approximations to truth differ.

Key Words: Anxiety, Dasein, Existence, Psychoanalysis.

\section{ANGUSTIA EXISTENCIAL COMO RUPTURA DEL CONVENCIONALISMO: DESOCULTACIÓN DEL SER COMO NADA}

\section{Analítica existencial del Dasein}

E concepto de angustia tomó una relevancia particular en el pensamiento contemporáneo. Posiblemente, el representante más notorio acerca de la reflexión de esta categoría fue Martin Heidegger. En particular, el análisis que lleva a cabo el pensador alemán acerca del concepto de angustia, se enmarca en el contexto de su analítica existencial del Dasein. Por esa razón, para entender de una manera profunda su particular concepción de la categoría de la angustia, será necesario realizar un lacónico recorrido por la caracterización que efectúa del Dasein. De esta manera, podrá apreciarse diáfanamente el papel que juega el fenómeno de la angustia en el entramado de la analítica existencial.

Si se dirige la atención a la propuesta filosófica del primer Heidegger, se advertirá que se encamina hacia el desarrollo de los elementos constituyentes de la existencia humana, como la vía directa para acceder al ser. Si la filosofía trascendental, propia de la Modernidad, se había caracterizado por su incursión en las estructuras que posibilitan el sujeto humano, en tanto y cuanto subjetividad epistemológica, la analítica existencial del Dasein (existenzialen Analityk des Daseins), que propone el pensador alemán, rompe con esta perspectiva, impugnándole "no haber tenido en cuenta que todo desempeño humano se deriva en último término de un ser-en-el-mundo originario" (Bech, 1999, p. 59). Expresado en otros términos, cualesquier aspiración de orden intelectual deberá ser tomada como una cuestión de segundo orden, ya que lo que caracteriza esencialmente al hombre-Dasein-es su estar-en-el-mundo(In-der-Welt-sein).

Partiendo de esta estructura mundanal se plantea que el sujeto deberá verse en términos de ente existente (Dasein). Ahora bien, cuando se habla de existencia, debe eliminarse toda connotación sustancialista que nos viene heredada de la interpretación tradicional (existentia como lo que está-ahí, Vorhandensein). Más bien, existir es una manera de remitirme a los poder-ser (Seinkönnen). Cabe destacar que la posibilidad es la proyección (Entwurf) del Dasein, el impulso esencial hacia aquello que todavía no es. A su vez, esta relación con las posibilidades es la comprensión. Por consiguiente, la comprensión (Verstehen) constituye el modo en el que la existencia es sus posibilidades.

En otro orden de cosas, cuando Heidegger hace referencia al mundo, no piensa en un conjunto de cosas que descubre el pensamiento, o en el medio en el que se 
englobaría la totalidad de lo existente. Si queremos alcanzar la esencia del mundo (mundaneidad del mundo, die Weltichkeit der Welt), debemos partir del mundo entorno (Umwelt). Las cosas, en medio de las cuales se halla el Dasein, se yerguen en objetos de atención, solicitud, se ofrecen a la mano (Zuhandenheit). Se tratan de cosas que sirven para algo; en definitiva, son útiles (Zeuge). De este modo, solo por el uso, la manipulación, que el Dasein hace de ellos, se accede a su ser. Asimismo, este ser de los útiles se alejará del ser propio del ente que se ocupa la ciencia o la percepción, el cual se caracteriza por la simple presencia (Vorhandenheit).

Pues bien, cuando el útil es dañado o se estropea es cuando se rompe el sistema de relaciones y remisiones respecto del cual es. Y es en ese instante en el que el útil se torna en simple presencia, por un lado, y, por el otro, el Dasein queda vuelto hacia la totalidad del sistema de remisiones. En este momento es donde se advierte que ese sistema de remisiones remite, en última instancia, al Dasein. Y es ahí donde llegamos al mundo como aquello que está siempre abierto y permite "absorberse atemática y circunspectivamente en las remisiones constitutivas del estar a la mano del todo de útiles. La ocupación es, en cada caso, como es, sobre la base de una familiaridad con el mundo" (Heidegger, 2003, p. 102). Así pues, el mundo solo es ese sistema en el que el Dasein está comprometido en su existencia. Dicho en otros términos, el estar-en-el-mundo se erige en la posibilidad fundamental que posibilita los infinitos poder-ser del Dasein.

No es de extrañar, una vez constatada esta estructura esencial, que Heidegger asevere que el Dasein se halla arrojado (Geworfenheit) en un mundo. Es decir, el hombre no asume su existencia cuando la comienza, sino que se encuentra en medio de posibilidades respecto de las cuales siempre está comprometido -o bien siempre ha aceptado o bien ha rehusado-.

Sin embargo, la comprensión, en tanto y cuanto es el modo de la existencia, no se encuentra de una forma indiferente en el mundo. Más bien, todo lo contrario, ya que el Dasein se comprende siempre en una determinada disposición afectiva (Befindlichkeit). Es decir, el Dasein, que se halla arrojado en medio de la infinidad de posibilidades, siempre está dispuesto de una determinada manera ${ }^{1}$. Expresado en términos heideggerianos, la disposición afectiva "es el modo de ser en el que el Dasein se entrega constantemente al "mundo" y se deja afectar de tal modo por él que en cierta forma se esquiva a sí mismo" (Heidegger, 2003, p. 163).

Si seguimos ahondando en la propuesta filosófica del primer Heidegger, apreciamos que en el momento en que el Dasein comprende su existencia como una posibilidad proyectada, en una determinada disposición efectiva, se esboza su caída (Verfallen) en el mundo. En particular, "el estado de caída en el "mundo" designa el absorberse en la convivencia regida por la habladuría, la curiosidad y la ambigüedad (Gerede, Neugier und Zweideutigkeit)" (Heidegger, 2003, p. 198). La habladuría (Gerede) es

1 No debe confundirse la Befindlichkeit con los estados de ánimo (esta consideración quedaría enmarcada en un horizonte óntico), sino que se trata de modos de ser en los que el Dasein siempre se encuentra. 
la propiedad de comprenderlo todo sin comprender propiamente nada. La curiosidad (Neugier) no se preocupa de ver para comprender, sino que solamente busca ver tan solo por ver. Por último, la ambigüedad (Zweideutigkeit) impregna el convivir, ya que el otro se hace presente en virtud de lo que se dice acerca de él.

Pues bien, estas tres formas constituyen la manera en la que el Dasein es cotidianamente, es decir, es el estado en el que el Dasein está caído (Verfallen), como se ha visto. Esta situación, a su vez, es provocada por el hecho de que el Dasein se halla inmediatamente en el mundo del que se ocupa. Dicho en otros términos, en el momento en que somos un ser-posible arrojado y dispuesto afectivamente, nos absorbemos en todo aquello que nos rodea, nos sumergimos en lo público de lo uno (das Man). Sin embargo, esta absorción en lo uno y el mundo representa una huida del Dasein ante sí mismo.

La caída es un estado esencial del Dasein, en el fondo, porque el ser de este es el cuidado (Sorge). El cuidado es un atenerse a la situación en la que ya se está arrojado, es decir, es un habérselas con los entes en medio de los cuales se está. Se da existencialmente antes que todo comportamiento teórico y práctico, tanto la teoría como la praxis deben ser entendidas como posibilidades de un ente cuyo ser es el cuidado.

Así pues, se aprecia que el Dasein es un ente cuyo ser es el cuidado. Sin embargo, en la mayoría de las ocasiones se encuentra en el modo de ser de la caída, es decir, es impropiamente (Uneigentlichkeit). Pero ¿qué es la propiedad (Eigentlichkeit)?, ¿cómo la alcanzamos? La respuesta es tajante: "vivir auténticamente (...) es vivir en la espera constante de la muerte y de su inminencia posible, mirar cara a cara a esta compañera de cada instante" (Mounier, 1990, p. 119). La muerte, la posibilidad de la imposibilidad de la existencia (Möglichkeit der Unmöglichkeit der Existenz), se yergue en el poder-ser propio (eigentlich) del Dasein.

\section{El 'Sein zum Tode' como horizonte de autenticidad}

De modo que el hombre no alcanza el cénit por ser una instancia que constituye intelectualmente el sentido del mundo, o bien por ser una sustancia pensante, sino que su máxima cima es ser-para-la-muerte (Sein zum Tode). Heidegger inicia su analítica de la muerte preguntándose si el Dasein será capaz de hacerse accesible por completo. Es decir, se plantea la cuestión si, en algún momento, seremos capaces de captar nuestra plenitud absoluta. Esta interrogación es esencial puesto que, en una primera instancia, parecería ir a redropelo de nuestro ser -el cuidado-. Debe recordarse que el cuidado se comporta siempre en relación con su poder-ser (können sein). Dicho de otro modo, el cuidado nos dice que el Dasein siempre es un ente incompleto, inconcluso, es una permanente inconclusión (ständige Unabgeschlossenheit). En el momento en que no tiene ya nada más pendiente es un no-existir-más. Consiguientemente, se puede colegir que "mientras el Dasein, en cuanto ente, 'es', jamás habrá alcanzado su integridad" (Heidegger, 2003, p. 257). 
No obstante, continúa cuestionándose Heidegger, ¿puede lograr, la experiencia de la muerte, conducir al Dasein a su estar-entero, a su integridad absoluta? Para contestar a esta cuestión será necesario un amplio rodeo por el fenómeno de la muerte.

En primer término, nos exhorta a que nos desembaracemos de todas las preconcepciones que tenemos respecto de ella. Es necesario despojarnos de estos prejuicios porque con ellos no alcanzaremos el auténtico fenómeno de la muerte. Mediante dichos prejuicios “el 'morir' es nivelado a la condición de un incidente que ciertamente hiere al Dasein, pero que no pertenece propiamente a nadie" (Heidegger, 2003, p. 277). Más aún, el análisis existencial de la muerte va más allá de estas presuposiciones, y, por ese motivo, debe preceder a toda metafísica, teología, psicología y biología de la muerte. Todas estas disciplinas nos presentan la muerte impropiamente al presuponer un determinado sentido de esta.

Para intentar columbrar el fenómeno, Heidegger pone el ejemplo del difunto. $\mathrm{Si}$ a este se le interpretase a partir de las exequias, de las honras fúnebres o del culto a su tumba, sería considerado como un objeto de ocupación (Zuhandenheit). Sin embargo, el difunto es algo más que un mero no-estar-más-en-el-mundo. La muerte, esencialmente hablando, no es el fin de un determinado proceso vital y, por esa razón, no tiene sentido hablar de un estar o no estar en el mundo. Más aún, este intento de alcanzar lo esencial de la muerte a partir de la experiencia del deceso del prójimo, no nos conducirá nunca a buen puerto. Ello es de este modo ya que la muerte, propiamente hablando, solo está en juego en primera persona. Cuando experimentamos el morir de los otros, no alcanzamos el verdadero sentido de este fenómeno -en contra de lo que apunta Levinas-, sino que, a lo sumo, asistimos a él. Lejos de esta consideración, "el morir debe asumirlo cada Dasein por sí mismo. La muerte, en la medida en que ella 'es', es por esencia cada vez la mía”' (Heidegger, 2003, p. 261).

La muerte no es una realidad que sobrevenga del exterior al hombre. Más bien, este la tiene en todo momento como posibilidad. No es una instancia ajena al Dasein, sino que se halla incorporada en su ser. Expresado en otros términos, mientras el Dasein está siendo es un no-todavía-muerto.

Así, pues, el morir es una posibilidad del Dasein en la que, aunque se consuma el curso de este, no se le agotan todas sus posibilidades específicas. El Dasein termina siempre inacabado, o, expresado metafóricamente, no necesita que llegue la muerte para alcanzar su madurez. Por esa razón, "la vida siempre habrá sido tan corta" (Derrida, 1998, p. 52). En particular, para Heidegger (2003):

Así como el Dasein, mientras esté siendo, ya 'es' constantemente su no-todavía, así él es también siempre ya su fin. El terminar al que se refiere la muerte no significa un haber-llegado-al-fin del Dasein sino un 'estar vuelto hacia el fin' (p. 266).

Esta es la propiedad de la posibilidad de morir: estar encarados hacia el fin. Únicamente de este modo, el Dasein alcanzará la propiedad al ser, en todo momento, el fin posible, al estar siempre a las puertas, al ser una inminencia. La muerte es una 
amenaza para con todas las posibilidades del Dasein, a las cuales las puede reducir, en cualesquier instante, a nada. En concreto, "su muerte es la posibilidad del no-poderexistir-más. Cuando el Dasein es inmediatamente para sí como esta posibilidad de sí mismo, queda 'enteramente' remitido a su poder-ser más propio" (Heidegger, 2003, p. 271).

Y es la posibilidad más propia puesto que el Dasein, en tanto y cuanto poderser, es incapaz de superar la posibilidad de la muerte. Su inexorabilidad es radical. En cuanto arrojado, el Dasein ya se halla inscrito en esta posibilidad. De este modo, la muerte se presenta como la posibilidad más propia, irrespectiva e insuperable.

\section{La angustia como antesala al 'Sein zum Tode'}

Es en este punto donde la angustia ${ }^{2}$ juega un papel esencial puesto que, en el momento en que el Dasein tiene angustia ante la muerte, es cuando propiamente existe. No obstante, esta afirmación podría resultar un tanto sorprendente si se la toma en su acepción cotidiana. En el lenguaje corriente, la angustia ante la muerte es el miedo al fin, el terror al abandono de la existencia. Sin embargo, para Heidegger, la angustia dista ingentemente de esta consideración.

Volvamos de nuevo al estado de la caída. En él, el Dasein queda absorbido por el mundo, lo cual le conduce a comprenderse desde aquello que le rodea y no a la sazón de sí mismo. En esta circunstancia, el Dasein existía impropiamente. Pues bien, el paso que determina la salida de la impropiedad a la propiedad viene dado por la angustia (Angst). Esta, a diferencia del miedo y demás disposiciones afectivas, no halla su objeto en el mundo -cuestión que posteriormente tanto Freud como Lacan retomarán- $\mathrm{y}$, consiguientemente, dicho objeto permanece indeterminado. A su vez, esta indeterminación revela al Dasein una especie de indeferencia para con todos los objetos que le circunscriben. Dicho de otro modo, "la angustia es una manera de ser en la que la falta de importancia, la insignificancia, la nada de todos los objetos intramundanos se torna accesible al Dasein" (Levinas, 2005, p. 119).

La angustia heideggeriana devuelve al Dasein al mundo, en tanto que tal, y lo arranca del mundo de lo útil. En particular, al hacer desaparecer las cosas intramundanas, la angustia imposibilita la comprensión de sí a partir de las posibilidades referidas a los objetos y, de este modo, conduce al Dasein a comprenderse a sí mismo a la sazón de sí mismo.

2 Al tratarse de un estudio lacónico, se hará referencia a la concepción de la angustia que Heidegger defiende en Sein und Zeit. Por esa razón no se podrá penetrar en los Prolegomena ni en los cursos acerca de la metafísica, en donde también se habla del fenómeno. No obstante, cabe destacar que las nociones que se defienden en estos dos pasajes no difieren de la temática que se defiende en SuZ. Esencialmente hablando, en las tres consideraciones se propugna un planteamiento análogo. Sin embargo, es notorio destacar que Heidegger inició su estudio acerca de la angustia en los cursos impartidos en 1925 y que son recogidos en los Prolegomena zur Geschichte des Zeitbegriffs. 
Pues bien, para Heidegger (2003) 'la angustia ante la muerte es angustia 'ante' el más propio, irrespectivo e insuperable poder-ser (Die Angst vor dem Tode ist Angst 'vor' dem eigensten, unbezüglichen und unüberholbaren Seinkönnen)" (p. 271). En el angustiarse, el Dasein queda vuelto hacia la posibilidad que es la muerte. Sin embargo, este estar vuelto no conlleva la realización de la muerte, al ser esta una posibilidad que debe ser comprendida, interpretada y sobrellevada como tal: la posibilidad de la imposibilidad de la existencia.

Ahora bien, este planteamiento que aborda Heidegger acerca del fenómeno de la angustia, así como de las consecuencias que acarreará, no es algo que pueda imputarse de una forma genuina a su discurso, sino que puede afirmarse sin ambages que tienen su génesis en el discurso kierkegaardeano. Dicho en otros términos, el análisis de la angustia heideggeriana se fundamentará, estructuralmente, tal y como se observará a continuación, en la doctrina de Kierkegaard acerca del fenómeno.

\section{Precedente de la angustia heideggeriana: Kierkegaard}

El planteamiento heideggeriano acerca de la angustia bebe de las fuentes kierkegaardeanas, tal y como se ha comentado con anterioridad. Sin embargo, para ver esta filiación discursiva, el estudio deberá penetrar lacónicamente en la noción kierkegaardeana de angustia. Para hablar de ella, Kierkegaard, en primer lugar, penetra en la estructura del hombre, tal y como ulteriormente efectuará Heidegger. La fractura entre los dos discursos se produce, ya que, según su parecer, el hombre es síntesis de alma y cuerpo. No obstante, apunta Kierkegaard, una síntesis de elementos contrarios no es concebible si no existe un tercer elemento que se encargue de unir dichos contrarios. Expresado en otros términos, es necesario un nexo de unión entre el cuerpo y el alma. En particular, este elemento, que tiene la función de aunar a los dos contrarios, es el espíritu.

La realidad espiritual consiste en ser "algo ambivalente. Por una parte es un poder amigo, puesto que une el alma con el cuerpo; por otra es un poder hostil puesto que se siente extraño al cuerpo, perturbando así dicha unión" (Suances, 1998, p. 243). Asimismo, en un primer momento, el espíritu se encuentra presente en la síntesis de una manera inmediata, que, ulteriormente, tiene que ser desarrollada. En una primera instancia, el espíritu está "como soñando" (Kierkegaard, 2007, p. 88), inconsciente de sí y de sus posibilidades. Se da, en este punto, un estado de inocencia que, más bien, es ignorancia. El hombre, en esta etapa, todavía no está determinado como espíritu y se halla en un estadio que puede ser calificado de infantil.

En este estado de infancia, el hombre, que todavía no es espiritual, aparece determinado como un ser vegetativo, animal, en el que, como se ha apreciado en anterioridad, su espíritu duerme. Es un momento en que desconoce toda diferencia entre el bien y el mal. Por esa razón, el hombre, en este momento, vive en paz. No existen, para él, ni la guerra ni el combate puesto que no existe nada contra lo que se deba luchar. No obstante, "la nada engendra angustia" (Kierkegaard, 2007, p. 87). En este 
primer estado, en el que no existe nada, se da la angustia. Mejor dicho, la inocencia es constitutivamente angustia.

Según Kierkegaard (2007), "la angustia que hay en la inocencia no es (...) ninguna culpa; y, además, no es ninguna carga pesada, ni ningún sufrimiento que no pueda conciliarse con la felicidad propia de la inocencia" (p. 88). Es decir, la angustia que se produce en la inocencia no tiene relación alguna con objeto determinado, sino que, por el contrario, viene generada por la nada. Esta manifestación de la angustia puede ser apreciada en los niños bajo el modo de un afán de "aventuras o de cosas monstruosas y enigmáticas" (Ídem).

Sin embargo, esta angustia, que se da en una primera manifestación en la infancia, adquiere otro cariz cuando, en el seno de la inocencia, emerge la posibilidad de la libertad y todas sus posibilidades. Cuando este hecho se produce, el espíritu comienza a salir paulatinamente de su ensoñación, para mostrársele la posibilidad de la libertad infinita, que, a su vez, brota de la nada de la inocencia.

No obstante, es notorio destacar que la posibilidad de la libertad, que emerge de esta nada de la inocencia, no radica en ser una elección entre lo bueno o lo malo. Si fuese de esta forma, existiría un cierto saber acerca de la libertad y sus consecuencias. Más bien, la libertad, en esta primera etapa, brota como posibilidad, y, a su vez, dicha "posibilidad de la libertad consiste en que se puede" (Kierkegaard, 2007, p. 99). Dicho en otros términos, el objeto de la angustia sigue sin ser nada concreto, sino que, en realidad, estriba en ser la posibilidad del ejercicio de la libertad, que se cierne sobre la nada (es decir, sobre las posibilidades y no la facticidad). De esta manera, el espíritu, que en una primera instancia estaba en ciernes y soñando, empieza a desarrollarse tras advertirse de su propia posibilidad ${ }^{3}$.

En todo momento, por consiguiente, el estudio de Kierkegaard se dirige hacia una angustia ante la posibilidad. Ahora bien, cuando se hace referencia a esta categoría, a su vez se está haciendo referencia, de una forma indirecta, a una determinada temporalidad. Es decir, lo posible corresponde, por completo, a lo futuro. De ahí que se relacione directamente la angustia con el futuro. Así pues:

Lo posible corresponde por completo al futuro. Lo posible es para la libertad lo futuro, y lo futuro es para el tiempo lo posible. A ambas cosas corresponde en la vida individual la angustia. De ahí que con un lenguaje exacto y correcto se enlace la angustia con el futuro (Kierkegaard, 2007, p. 167).

Solo el futuro goza de esta constitutiva angustia. Ni el presente ni el pasado podrán engendrarla. En particular, en referencia al pasado, este jamás puede angustiar, ya que para que este hecho se produzca es necesario que entre en una relación de posibilidad para con el individuo. Sin embargo, como se ha apreciado con anterioridad,

\footnotetext{
${ }^{3}$ Kierkegaard ilustra todo el proceso de la irrupción de la posibilidad de la libertad, con el relato bíblico de Adán y Eva.
} 
la posibilidad es una categoría que corresponde por completo a la dimensión de lo futuro. Por consiguiente, el pasado, considerado en sí mismo, no genera angustia, sino solo en tanto y cuanto posibilidad de volver a repetirse, es decir, hacerse futura. A lo sumo, una acción pasada puede generar arrepentimiento o beneplácito.

Kierkegaard (2007) da un paso más en su exposición de la angustia al afirmar que "la angustia es el estado psicológico que precede al pecado" (p. 168). Debe hacerse notar que toda la reflexión kierkegaardeana acerca de la angustia gira en torno al concepto de pecado. La pecaminosidad de la existencia humana no viene dada por el hecho de que Adán pecó en un momento determinado. Más bien, Adán, y todo hombre posterior, se hace culpable tras salir del estado de inocencia mediante un salto cualitativo. Asimismo, la angustia se erige en la condición para que dicho salto se produzca. De ahí que se convierta en el último estado psicológico a partir del cual irrumpe el salto cualitativo que, a su vez, introducirá el pecado.

Si vamos al relato bíblico del Génesis, recordemos que Dios manda a Adán que no tome los frutos del árbol de la ciencia del bien y del mal. En ese momento emerge en Adán la posibilidad de poder. Ahora bien, la prohibición divina, además de plantear la angustia de la posibilidad, introduce una tensión radical entre el hecho de emprender la acción, por un lado, y, por el otro, el fenómeno de calcular sus consecuencias. Dicho en otras palabras, se produce, en el seno de Adán, un estado de completa ambigüedad en la que se desea, pero que, simultáneamente, se teme la acción que se va a llevar a cabo. En este punto, Adán todavía no es culpable (puesto que no ha cogido la manzana del árbol de la ciencia), sin embargo, se ha efectuado una ruptura con el estado de inocencia anterior, como si esta se hubiese perdido en forma definitiva. Finalmente, y una vez cometida la acción punible, se ha producido un salto que va de la inocencia, que en realidad es ignorancia, a la experiencia del bien y del mal. Mediante el pecado se establece el saber acerca de lo que es el bien y el mal.

Pues bien, todo este proceso le ocurre a todo individuo antes de emprender toda acción que puede introducir, de nuevo, el pecado en el mundo. Este, como en múltiples ocasiones apunta Kierkegaard, continúa viniendo. No se introdujo de una vez y para siempre en sazón del pecado de Adán, sino que sigue viniendo constantemente a partir de las acciones de los individuos.

Una vez cometido el pecado, hay toda una serie de consecuencias. En primer término, como se reseñó anteriormente, tras el pecado el hombre se hace culpable saliendo, de esta manera, del estado de inocencia. Tras pecar, el hombre abandona esa etapa de ignorancia para tener un saber determinado acerca del bien y del mal.

Otra consecuencia del pecado es que trae consigo los remordimientos. No obstante, estos no tienen la capacidad de abolir la acción pecaminosa, sino que, más bien, lo único que pueden hacer es entristecerse de él.

No obstante, las consecuencias más importantes que el pecado introduce radican en el establecimiento de dos tipos de angustia: La angustia objetiva y la subjetiva. La primera hace referencia a la angustia que se halla en la naturaleza. Para Kierkegaard (2007), "la sensibilidad se hace pecaminosa una vez que el pecado vino al mundo y cada 
vez que el pecado viene al mundo" (p. 115). En este contexto, la sexualidad entraña angustia puesto que el espíritu se advierte no únicamente que se halla determinado en tanto que pertenece a un cuerpo, sino que, además, que se encuentra inmerso en un cuerpo con una determinada diferencia sexual ${ }^{4}$.

En segundo lugar, la angustia subjetiva es aquella que se encuentra "instalada en el individuo como consecuencia de su propio pecado" (Ibídem, p. 111). A partir de este momento, todo ejercicio de la libertad entrañará angustia, ya que cabrá la posibilidad de repetir la acción pecaminosa que se ha llevado a cabo.

Analizadas las consecuencias del pecado, debe destacarse el hecho que, para Kierkegaard, el hombre, tras pecar, puede angustiarle el estar inmerso en la culpabilidad. Es decir, cabe la posibilidad de que el individuo sienta angustia del pecado cometido. Este hecho significa que el hombre todavía se encuentra inmerso en el bien, al angustiarse por estar en el mal y, por ese motivo, tener la voluntad de escapar de él. Ahora bien, hay toda una serie de individuos, según el pensador danés, que se encuentran dichosos por hallarse en el mal. Es decir, no se angustian por estar en el pecado y, por ende, en el mal, sino que se angustian por el bien. A este fenómeno que le acontece a una serie de hombres, Kierkegaard (2007) designa como lo demoníaco. En este estado, el individuo "se angustia ante el bien" (p. 218) y, por esa razón, la libertad se establece como no-libertad. Dicho en otros términos, en el estado de endemoniamiento la libertad se establece como posibilidad rechazada 5 .

El hombre demoníaco, más allá de estas consideraciones, se caracteriza también por una voluntad de ensimismamiento. Expresado en otros términos, el endemoniado es aquel tipo de individuo que tiene la voluntad de encerrarse en sí mismo, sin querer tener ningún tipo de contacto con otra cosa que no sea él mismo.

Al ser la angustia la posibilidad de la libertad, lo es también de la infinitud. En la posibilidad, todo es posible, tanto el éxito como el fracaso. Cuando se toma conciencia de que cualesquier desgracia es posible, o, lo que es peor, que puede repetirse,

${ }^{4}$ Relacionado con la temática de la sexualidad, Kierkegaard apunta que en el momento de engendrar, es cuando la angustia es más intensa, ya que es el instante más ajeno al espíritu. Al dar a luz, el espíritu de la mujer queda en suspenso y, por ese motivo, no lleva a cabo ninguno de sus cometidos. Así pues, puede afirmarse sin reservas que cuanta más angustia haya, tanta más sensibilidad existirá.

Asimismo, debe destacarse que la diferencia sexual, de la misma manera que la pecaminosidad de la sensibilidad, viene introducida por el pecado.

5 Esta pérdida de la libertad puede darse bajo múltiples formas: En primer término, el cuerpo debe subordinarse al alma y, por ende, al espíritu. Ahora bien, si el cuerpo es capaz de rebelarse contra esta determinada disposición, se introducirá la no libertad como lo demoníaco. Dicho sucintamente, cuando el cuerpo adquiere la primacía ontológica se pierde la libertad.

En segundo término, la pérdida de la libertad puede darse de la siguiente manera: Kierkegaard destaca que la verdad o, mejor dicho, certeza, se produce en un actuar. No obstante, la actuación es lo más propio de la individualidad concreta, de la conciencia, del individuo. La conciencia que tiene el individuo de sí mismo jamás puede ser una pura observación, ya que el individuo, al actuar, deviene. Así pues, la conciencia de sí siempre será un acto. Ahora bien, Kierkegaard denomina a este acto interioridad. De esta forma, la interioridad, que únicamente se da en la acción y por la acción, se erige en el contenido más concreto de la conciencia del individuo. Pues bien, siempre que la interioridad no responda a este tipo de conciencia actuante, se producirá lo demoníaco y, consiguientemente, la pérdida de la libertad. 
se advierte que la posibilidad es una categoría más dura que la facticidad. De esta forma, aquel que haya recorrido la angustia de la posibilidad, todos los avatares de la vida le resultarán insignificantes (no obstante, con ello no se elimina la angustia. Una vez el hombre ha pecado, y sin haberlo cometido, siempre la llevará consigo).

Asimismo, al dirigirse la angustia a la posibilidad y, por ende, a la infinitud, nos muestra, como se ha destacado, que las cosas finitas son insignificantes si se ponen al lado de la posibilidad. El afán de poder, el ánimo de lucro y demás cosas pierden toda relevancia. En el reino de la posibilidad solo cabe lugar a la fe, ya que en ninguna otra instancia puede hallarse el reposo. En consecuencia, la angustia debe conducir a la fe y, ulteriormente, esta debe ayudar a la angustia para conducir al individuo a la Providencia divina.

\section{ANGUSTIA, OBJETO Y DESEO: EL PSICOANÁLISIS COMO EXPERIENCIA SUBVERSIVA}

\section{La angustia en la clínica psicoanalítica lacaniana: en los márgenes de lo simbólico y lo imaginario}

El psicoanálisis es una praxis clínica moderna (nace con Freud a principios del siglo XX), pero también una experiencia que opera una torsión sobre el lenguaje mismo. Esta segunda consideración se puede enmarcar en la relectura de Freud que realizó el psiquiatra y psicoanalista francés Jacques Lacan en lo que se conoce como el primer tiempo de su enseñanza, también denominado "el retorno a Freud", en la década de los 50 y algunos años de la década de los 60. Este tiempo clínico y teórico de Lacan será la referencia conceptual de este segundo bloque, y más concretamente sus consideraciones a lo largo de su décimo seminario, titulado "La angustia", e impartido entre 1962 y 1963.

La de su tesis capital de su primera enseñanza es mostrar que el inconsciente está estructurado como un lenguaje, señalando así el registro simbólico como el eje crucial de la cura analítica. El eje simbólico, que articula al sujeto en su relación al Otro en tanto orden simbólico donde se constituye el sujeto, pues le precede ${ }^{6}$, se encuentra siempre en tensión con lo que es del registro imaginario, en el que Lacan ubica la relación transferencial intersubjetiva del psicoanálisis postfreudiano. El otro es pues el semejante al que uno se identifica imaginariamente, mientras que el inconsciente es la Otredad misma, esa Otra escena donde se juega la lógica afectiva del sujeto: el inconsciente. Es propiamente la red significante, constituida de forma contingente, que carece de sentido por sí misma, pero lo produce con relación al registro imaginario.

Así, tomar al analista como una imagen ideal a la cual uno se debe identificar al final del recorrido analítico, no es otra cosa que concebir la experiencia analítica en el

\footnotetext{
${ }^{6}$ Lacan, 2006, p. 175.
} 
plano de la comprensión y del sentido. No en vano esta es sancionada por Lacan como una práctica del psicoanálisis que olvida la lectura crucial del primer Freud, a saber, que el inconsciente emerge por y en la palabra: eso que del significante toca el cuerpo.

Para Lacan, como para Freud, la tensión entre registros de diversa índole forma el núcleo de la estructura subjetiva pero también de la experiencia analítica. Esto es: en una dirección, el fenómeno significante, patente en los olvidos, los juegos de palabras, o los equívocos; de forma cruzada, en la dirección opuesta, la transferencia, el narcisismo, la lucha por el reconocimiento del semejante que Lacan toma del seminario de Kojève sobre Hegel.

Lacan (1964/2008) esquematiza con absoluta sencillez este primer tiempo clínico-teórico mediante el esquema L, que podemos hallar en el volumen 2 de sus 'Escritos' (p. 525).

Imaginario y simbólico son pues los registros privilegiados de estos primeros años de seminarios de Lacan, y su articulación conforma la estructura subjetiva, lo que podría pensarse como equivalente a la realidad psíquica en Freud. Hay, sin embargo, un límite: por fuera, un tercer registro, inasimilable por los dos anteriores, que Lacan nombra real, da cuenta de la realidad externa, inasimilable por parte del sujeto. A medida que avance la enseñanza del psicoanalista francés este real dejará de considerarse como la realidad inasible en análisis para acabar siendo el imposible mismo que orienta la práctica analítica. Si el significante cauteriza una marca sin sentido en el cuerpo del sujeto que sirve de origen y meta al circuito pulsional, la inscripción del significante recorta una exterioridad irrepresentable que Lacan trató de circunscribir. Así, su supuesta alineación entre las filas del estructuralismo es cuanto menos fallida, ya que desde el principio (y cada año de forma más evidente) el núcleo del psicoanálisis era propiamente aquello que lo simbólico no aísla y lo imaginario no da forma.

Es la forma en que Lacan acabó por tomar la pulsión de Freud, en los límites de la cual halló un registro cuya dimensión solo puede aprehenderse en su semblante de trauma. Es el límite interno a la estructura misma.

De este real, una experiencia analítica auténtica puede, por el rodeo de la mentira de lo simbólico, aislar una parte, una vacuola ${ }^{7}$, como resto sintomático de eso que no es otra cosa que una operación de palabra segmentada por la interpretación del analista. La señal del encuentro mediado con un real... eso es propiamente la angustia. Veremos que el encuentro viene mediado por un objeto...

Ya Freud mantuvo con la angustia un diálogo equívoco. ¿Era con objeto, o sin objeto? Si Freud señaló (como Kierkegaard) que presentaba un carácter de indeterminación y que era sin objeto ${ }^{8}$, Lacan nos recuerda que no pudo callarse ahí dónde algo le hablaba, lo confiesa en la frase anterior: la angustia es angustia ante "algo" . Es también reacción o señal ante la pérdida de un objeto interno, indefinido; un

\footnotetext{
7 Miller, 2004, p. 51.

8 Freud, 1926/1992, p. 154.

9 Lacan, 2006, p. 171.
} 
estado afectivo que sigue a una imagen mnémica ${ }^{10}$. Freud lo ejemplifica tomando la angustia frente al caballo del pequeño Hans ${ }^{11}$, fenómeno que interpreta como una desviación de la angustia frente a la castración. Hay en este caso desplazamiento del afecto de angustia a una representación mnémica u objeto que sustituye la amenaza de castración ${ }^{12}$. Se trata pues de una respuesta desplazada frente a un temor exterior, el de la castración, temor exterior que es la respuesta frente a la pulsión, por sí misma inofensiva. El objeto original de la angustia queda así reprimido.

Lacan, a lo largo de su seminario sobre la angustia, aclara la complejidad del fenómeno y despeja el bosque freudiano en torno al objeto de este afecto.

\section{El objeto de la angustia: castración, deseo y fantasma}

Lacan señaló en varias ocasiones que su único aporte relevante a la teoría psicoanalítica era la invención y formalización de lo que llamó el objeto a. Este objeto, susceptible de ser producido a lo largo de una experiencia analítica, es el objeto causa del deseo y a la vez el objeto de la pulsión. Es, además, el objeto propio a la angustia.

Si en "Inhibición, síntoma y angustia" la angustia es el tema principal, como señala Strachey ${ }^{13}$, no es este texto el que le parece el más propicio a Lacan para estudiar la angustia en Freud. Lacan se dirige a "Lo ominoso"14. Sí, lo ominoso para Freud es lo que despierta angustia u horror ${ }^{15}$.

Lo primero que se puede decir de este texto es que pone de relevancia la importancia que Freud acordaba al análisis lingüístico. Freud (1919/1992) examina al inicio de este texto, en varios idiomas, la particularidad de los supuestos opuestos heimlich y unheimlich, lo familiar frente a lo siniestro (pp. 220-226). Pero halla un significado de heimlich que no es el habitual, pues remite a algo oculto, secreto... y encuentra que justamente lo unheimlich puede también tener este valor, de algo oculto o secreto que ha sido revelado. Es pues en esta ambigüedad del uso de los significantes que encontramos la dialéctica del velo. Hay familiar en lo siniestro.

Apoyándose en el estudio médico-psicológico de la estética de Jentsch, Freud señala que el afecto de lo siniestro surge ante la figura de cera o el autómata, ante la epilepsia o la locura ${ }^{16}$. Pero Freud se apoya en algo más concreto, el relato de "El hombre de arena" de E.T.A Hoffman.

En este relato, no es preciso extenderse, se trata de un objeto: los ojos de la bella autómata Olimpia, separados de su cuerpo. Son el resto libidinizado que lleva al protagonista a arrojarse al vacío, al grito de “'Sí, bellos ojos, bellos ojos!”. He

\footnotetext{
10 Freud, 1926/1992, p. 89.

11 Ibídem, op. cit., pp. 97-103.

12 Freud, 1926/1992, p. 104.

13 Freud, 1926/1992, p. 74.

14 Lacan, 2006, p. 57.

15 Ídem.

16 Freud, 1919/1992, p. 227.
} 
aquí la marca de un deseo que lleva a la muerte, representante de la castración. No en vano Freud recuerda que la posibilidad de perder los ojos es un motivo importante de angustia, y es un sustitutivo de la angustia de castración ${ }^{17}$.

Encontramos pues, nuevamente en Freud, la articulación siguiente: objeto, pérdida, deseo, angustia y castración. Esta articulación se puede seguir nítidamente en el seminario $\mathrm{X}$ de Lacan.

El objeto de la angustia es un pedazo separado del cuerpo del Otro, nos dice; un recorte. Aquí el Otro de lo simbólico está encarnado, y detiene el objeto propio a la satisfacción (el pecho de la madre, objeto de la pulsión oral, es aquí el ejemplo más sencillo). Pero la angustia implica ahí al sujeto mismo, pues este objeto viene a nombrar eso que le falta, siendo propiamente el velo de la castración. Así, la dialéctica en torno a lo siniestro transmuta a la articulación entre el sujeto y el Otro.

El objeto a, objeto de la angustia, es el resto de la división que se produce entre el sujeto y el Otro ${ }^{18}$, siendo esta una división marcada por la castración. Hay pérdida de los dos lados. Lacan lo ilustra con el parto, referencia que hallamos en Kierkegaard cuando estudia la angustia, cuestión que Freud retoma para señalar su importancia, a la vez que niega que toda angustia remita a la angustia originaria del bebé en el momento de la separación de la madre. No en vano, la angustia tiene relación al significante, a la representación mnémica, como veíamos en el punto anterior... y el neonato no habla.

Por ello Lacan no se entretiene en la angustia supuesta del bebé al separarse de la madre en el parto (si existiera, sería imposible de tratar en el dispositivo analítico, pues es un dispositivo de lenguaje): se interesa por la pérdida, la caída de un resto, la placenta ${ }^{19}$; ese objeto es el desecho, lo que pertenecía si se quiere a ambos y no pertenece a ninguno cuando se pierde.

¿Qué relación entre este objeto, más bien siniestro, y el deseo? ¿Y cómo se trata a partir del significante?

La estructura del deseo supone la castración, ya que uno desea ahí donde le falta. Y lo que uno desea es siempre otro objeto, pues en cuanto goza del objeto que deseaba no puede mantener ahí el deseo mismo. Por ello, Lacan pensaba el plano del deseo con relación a la metonimia: uno desea una parte del todo que siempre está en otro sitio. Eso sí: la metonimia implica el significante, pues el deseo en el humano se desliza por el discurso.

Lacan defiende que el deseo es deseo del Otro, y esto se presta a múltiples lecturas: el sujeto desea al Otro, el deseo pertenece al Otro, es el Otro el que desea... Es propiamente una dialéctica, en la que hay que recordar que el objeto queda del lado del Otro, es un recorte del cuerpo del Otro $^{20}$. Por eso el análisis no se hace en soledad, sino con un analista.

\footnotetext{
17 Freud, 1919/1992, p. 231.

18 Lacan, 2006, p. 36.

19 Ibídem, p. 181.

${ }^{20}$ Lacan, 2006, pp. 31-32.
} 
El estatuto de este Otro depende desde donde se piense; para Hegel, este Otro era el Otro de la conciencia, el que mira. Para el psicoanálisis, el Otro es inconsciencia.

La particularidad del deseo justamente pasa por la lógica del no saber lo que uno desea, siendo la solución constituir al otro como lo que me falta, sin saber qué me falta ahí exactamente ${ }^{21}$. Por ello, es en la imagen del otro como el sujeto consigue vestir el objeto a, objeto reprimido en tanto es el objeto de satisfacción. El objeto a, por tanto, no puede pensarse como el objeto de la epistemología: no es cognoscible, sino que es producto de la operación significante del análisis ${ }^{22}$.

Lo familiar en la angustia es la presencia del objeto desvelado, de ese objeto que está en el centro de la Otra escena freudiana, ese objeto que es a la vez lo más íntimo y lo más extraño de la vida fantasmática del sujeto.

\section{Lacan: Heidegger, del Dasein al ser de goce}

Aunque Lacan (2006) es hegeliano, sin duda, en 'La angustia' señala que del filósofo del que se halla más cerca es de Heidegger (p. 16); en su Dasein, en el desamparo del ser para la muerte. ¿Qué encontró Lacan en la obra de Heidegger? En esta cita, extraña fundamentalmente la cuestión del desamparo... En efecto, es más bien una diferencia radical la que hallamos en un primer abordaje, ya que si en el caso del filósofo la ocultación y desocultación de la verdad que permite llegar al Dasein es una praxis llevada a cabo en soledad, en el psicoanálisis la experiencia pasa por un Otro encarnado, es decir, no puede encaminarse sino mediante la transferencia...

La referencia al ser es pues capital para ambos autores, pues ambos diferencian el ente del ser, problematizando claramente las relaciones del ser en el mundo, del sujeto con el objeto. Quizás señalar la distancia de sus discursos con el discurso de la ciencia contemporáneo ponga de relevancia esta cuestión. Suponer, como hacen hoy las neurociencias y la población cientificista, que el sujeto es el cerebro, no es otra cosa que suponer un ser en el ente, llevar la lógica de la metafísica a su última consecuencia: usted es "eso", puesto que "eso" existe y no "hay" nada más. Es la imposibilidad para aceptar la realidad de la castración en lo simbólico, la falla propia al lenguaje para nombrar el goce, siendo esta la marca fundadora que constituye al sujeto como deseante. El sujeto en su división, y el hecho de que goza ahí donde sufre y ahí donde obtiene placer, son cuestiones forcluidas por la ciencia. El hombre es para el discurso de la tecnociencia un Todo, en el que el deseo equivale a la necesidad y tiene su objeto, y la imagen de sí mismo o self equivale a lo que uno es. No hay más que la apariencia, y la relación al objeto es satisfactoria. Para Lacan y Heidegger, esto era una falacia, y su concepción de la experiencia llevaba a su destitución.

En la referencia al ser en el mundo también podríamos localizar una cercanía entre el filósofo y el psicoanalista. Para Lacan, hay en el origen, antes del sujeto,

\footnotetext{
21 Lacan, 2006, p. 37.

22 Ibídem, p. 48.
} 
un mundo ${ }^{23}$ : es propiamente el lugar del lenguaje, del Otro. Es un mundo en el que hay una falta, y es un mundo por ello siempre abierto, como veíamos que es para Heidegger en el primer punto del primer apartado. Después, de este mundo en el que uno es arrojado, se recorta un marco, el fantasma. Este sería, podríamos aventurarnos, su ser en el mundo. Allí donde para Heidegger el Dasein es inauténtico a causa de todos los objetos útiles que pueblan y le preceden en su Umwelt, Lacan señala que la representación del sujeto por la cadena significante, mediante la alienación, es inauténtica. Esta operación es paralela para los autores (Alemán \& Larriera, 1996, p. 41).

Pero el psicoanálisis trata con un ser de goce, podríamos añadir, otorgado por el recorte-desecho del cuerpo del Otro que constituye el objeto a... Aquí, se abre una brecha entre estos pensadores: el campo del psicoanálisis, lo que revela y va más allá de la filosofía, es la cuestión del goce ${ }^{24}$. Así, Lacan escribe el fantasma como la articulación entre un sujeto dividido, marcado por la castración simbólica que lo hace un sujeto deseante, y un objeto de goce siempre perdido, estructuralmente separado: el objeto a. Es propiamente esta separación, y el circuito significante que origina, lo que constituye el motor de la pulsión freudiana. La experiencia de lo real para un sujeto pasa por el encuentro con este objeto, y es propiamente un encuentro con lo in-mundo ${ }^{25}$; el fantasma no es una disposición afectiva, sino el marco de un rechazo que trata de obturar lo insoportable. La angustia, afecto que da cuenta de la presencia del objeto, introduce lo traumático, lo in-mundo.

\section{El psicoanálisis: subversión del sujeto, subversión del deseo}

¿Y qué tiene de subversivo la experiencia analítica? Nos atrevemos a decir que es propiamente la función del corte lo que revela al sujeto que su suposición de ser es en verdad una posición de goce. Ahí donde se imagina representado por una imagen de sí, la interpretación analítica, que opera mediante el corte de la cadena de discurso que produce el que se analiza, remite a aislar un significante fuera de sentido, y así le revela su lugar de enunciación que desautoriza al yo ${ }^{26}$. El sujeto emergente es el sujeto del inconsciente, el sujeto del deseo.

Ahí donde uno cree que es, la operación del discurso del analista extrae el goce de la insignia a la que uno se identifica, ubicando el objeto de goce fuera, produciéndolo, aislándolo. Es un atentado contra el narcisismo. Usted no es eso. Eso cae, y uno se encuentra con su falta en ser, y su añadido de goce estúpido.

23 Lacan, 2006, p. 43.

24 Ibídem, p. 67.

25 Lacan, 1966/2008, p. 761

26 Zaidel, R. (2007). "Punto vivo" del seminario del Campo Freudiano de Barcelona. Jean Lacan. Nodvs, L'Aperiòdic Virtual de la Secciò Clínica de Barcelona, XXII. 1-3. Reseña del comentario de Vicente Palomera de los capítulos X y XI de La angustia, realizado en el Seminario del Campo Freudiano de Barcelona de junio de 2007. Recuperado de http://www.scb-icf.net/nodus/. 
Lo que el psicoanálisis revela, y eso es de interés para la política, es que no hay lazo universal que evite la segregación, pues en cada sujeto la posición de goce propia es segregada ${ }^{27}$. El odio del otro es propiamente el odio del goce que sabemos más propio que ajeno. El malestar en la cultura es justamente eso, el goce, lo inútil con lo que nos topamos una y otra vez, la pulsión freudiana ${ }^{28}$, la imposibilidad de no repetir, el estancamiento de la misma escena en la que uno es objeto e imagen. Todo ello, para que el deseo más íntimo se viva como imposible, o como insatisfecho. La tendencia imperante, suponer que la culpa es de Otro, se revela como una falacia: uno está activamente en eso de lo que se queja.

Angustia y deseo colindan en un punto crucial, que es el que revela propiamente la experiencia analítica, el que está en el corazón de la ruptura narcisista: hay castración. Uno desea desde la castración, y es ahí donde más desconoce; desconoce el objeto causa de su deseo. Cuando la castración se revela, lo hace mostrando la presencia del objeto inmundo, de los ojos del autómata: estamos en el reverso, el desvelamiento de lo que debe permanecer velado para que el circuito repita, ciego.

Es preciso decir, educar incluso (puesto que muchos jamás querrán pasar por la experiencia analítica, y se contentarán con denigrarla o burlarse de ella desde la ignorancia) que hay goce perdido para siempre jamás. El capitalismo consumista contemporáneo promete, impone, el más de goce: usted puede gozar un poco más. Pero el objeto nunca será ese, y cuanto más se busque, más se encontrarán con una angustia desbordada, inoperante, quedando suspendidos en el imposible de alimentar la nada.

\section{REFLEXIONES EN TORNO AL VELO:}

\section{DE LA SOLEDAD A LA TRANSFERENCIA}

El título del presente trabajo podría dejar entender al lector que el velo sería un biombo que permite alternar entre la angustia y lo real. Si en efecto existe función de bisagra entre la angustia y lo real, siendo esta para el psicoanálisis la señal de la inmixión de lo real en el campo del sujeto, es preciso precisar que el velo no es justamente el telón, sino lo que este oculta.

El velo, es propiamente la escena que el inconsciente dispone. Lo que queda en tinieblas es la mirada de una masa indefinida, los espectadores. Ahí tendríamos el objeto. Lo más cerca que uno puede estar de lo real, es aquel instante en que el actor, angustiado, espera la intervención de una voz, la del apuntador, que enmudece. No hay apuntador, y no se sabe cuándo podría aparecer, pues no hay saber, ley o predicción que permita asirlo. Lo real en psicoanálisis puede por esta vía acercarse a la noción de posibilidad que veíamos en el existencialismo.

\footnotetext{
27 Alemán \& Larriera, 1996, p. 14.

28 Ibídem, p. 17.
} 
En Lacan y Heidegger está presente la idea del velo, solidaria de la noción de ilusión, o de inautenticidad. Es algo que también encontramos en Freud, verdadero mago de Oz que supo revelar la verdad de la escena tras la razón.

Heidegger retoma como vemos la noción de posibilidad que se puede leer en Kierkegaard como propiedad del ser auténtico. El ser es potencia con relación a un mundo. La autenticidad es posible ahí donde el Dasein, vía la angustia, encara su verdad: su finitud, la propia, imposible de aprehender mediante el fallecimiento del semejante. Hay una radicalidad de la muerte que va más allá de la identificación, un punto opaco que agujerea el mundo, que ya entrevemos en Heidegger mundo de lenguaje, mundo a la mano del ser. La muerte es lo real del primer Heidegger. Es la Verdad a la que se llega en silencio, en la integridad de un encarar la muerte.

Lacan se ubica en el campo analítico dando prioridad a otra verdad: la de la pulsión. La verdad es ahí donde un decir afecta el cuerpo. Curiosamente, a ello se llega por la vía de la habladuría, aquella que Heidegger denuncia como inauténtica: la pulsión está en ese runrún que insiste, tontamente, en el más allá de la comprensión. El afecto verdadero por antonomasia que surge en ese límite, como veíamos, es la angustia. Pero si toca la pulsión, es justamente en el lugar en que la satisfacción es no natural. En este sentido, Lacan está más cerca de Kierkegaard en lo que refiere a la verdad que traería consigo la angustia: estamos ante el pecado. A medida que avanza en su enseñanza, la verdad en Lacan se vacía, pierde su sustancia, para señalar que tiene estructura de ficción. Tiene estructura de ficción porque no hay verdad sino por su efecto, siempre que estemos en el campo del Otro, impotente finalmente para nombrar el encuentro entre dos cuerpos sexuados.

Como señalábamos anteriormente, los puntos de divergencia, de imposibilidad, para equiparar el discurso lacaniano al heideggeriano provienen sin duda de aquello que la praxis determina. La praxis de Heidegger invita a la ascesis, a esperar cierta revelación en la contemplación de una muerte siempre presente. El Dasein está siempre por acontecer, pero su advenimiento, si bien mediado por cierta ruptura de la relación mundana a los objetos, se da en aislamiento.

La praxis analítica requiere del amor de transferencia, de un primer engaño que pasa por suponer el saber en un Otro que se encarna en el cuerpo del analista. El cara a cara en el consultorio, y la dimensión de la confesión de los pecados, es la primera escena. Lo radical de la experiencia se introduce cuándo por la vía del sueño y otras formaciones del inconsciente irrumpe la dimensión de la pulsión que toca el campo de la verdad. Decantar esa esencia lleva, cada vez más, a la ruptura con el saber en el analista, para apuntar en espiral a lo indecible, el objeto éxtimo a uno mismo, el lugar del odio como último velo a la incomprensión radical. En este segundo tiempo del tránsito el analista encarna no ya el saber, sino al objeto mismo en su radical extrañeza. Estamos un poco más lejos de la escena, y al final de la obra queda, a lo sumo, un nombre propio sin sentido que permite una nueva forma de inscribirse en el vínculo social. 


\section{REFERENCIAS}

Alemán, J. \& Larriera, S. (1996). Lacan: Heidegger. Buenos Aires: Del Cifrado.

Derrida, J. (1998). Aporías: Morir-esperarse (en) los límites de la verdad. Barcelona: Paidós. Bech, J. (1999). De Husserl a Heidegger: La transformación del pensamiento fenomenológico. Barcelona: Universidad Barcelona.

Freud, S. (1919/1992). Lo ominoso. En Obras Completas de Sigmund Freud (Tomo XVII). (pp. 215-251). Buenos Aires: Amorrortu.

Freud, S. (1926/1992). Inhibición, síntoma y angustia. En Obras Completas de Sigmund Freud (Tomo XX). (pp. 71-164). Buenos Aires: Amorrortu.

Heidegger, M. (2003). Ser y Tiempo. Madrid: Trotta.

Kierkegaard, S. (2007). El concepto de la angustia. Madrid. Alianza.

Suances, M. (1998). S. Kierkegaard: Trayectoria de su pensamiento filosófico (Tomo II). Madrid: Cuadernos de la Universidad Nacional de Educación a Distancia.

Lacan, J. (1966/2008). Escritos (Volumen 2). Buenos Aires: Siglo XXI.

Lacan, J. (2006). El Seminario de Jacques Lacan, libro 10: La angustia, 1962-1963. Buenos Aires: Paidós.

Levinas, E. (2005). Descubriendo la existencia con Husserl y Heidegger. Madrid. Síntesis.

Miller, J. A. (2004). La experiencia de lo real en la cura psicoanalítica. Buenos Aires: Paidós. Mounier, E. (1990). Obras completas (Tomo Segundo). Salamanca: Ermeneia.

Sartre, J. P. (1998). El ser y la nada. Buenos Aires: Losada.

Zaidel, R. (2007, junio). "Punto vivo" del seminario del Campo Freudiano de Barcelona. Jean Lacan. Reseña del comentario de Vicente Palomera de los capítulos X y XI de La angustia realizado en el Seminario del Campo Freudiano de Barcelona. Nodvs. L' Aperiòdic Virtual de la Secciò Clínica de Barcelona, XXII. 1-3. Recuperado de http:// www.scb-icf.net/nodus/. 